DOI: https://doi.org/10.30749/2594-8261.v3n1p69-98

\title{
A PREPARAÇÃO DE ELENCO QUE REVOLUCIONOU A INTERPRETAÇÃO DE ATORES NO BRASIL: FÁTIMA TOLEDO E O MÉTODO FT - BASEADO EM ATUAÇÕES REAIS.
}

\section{THE PREPARATION OF THE CAST WHICH REVOLUCED THE INTERPRETATION OF ACTORS IN BRAZIL: FÁTIMA TOLEDO AND THE FT METHOD - BASED IN REAL ACTING.}

Resumo: Através de uma perspectiva entre a interpretação de atores e as linguagens inseridas no contexto da arte dramática, este artigo expõe a capacidade de opções em instrumentos técnicos e teóricos que o Método Fátima Toledo (também chamado de "Método FT") colabora de maneira positiva e única, pela forma na maioria dos projetos em que a preparação é encontrada, tornando-as peculiares. Com isso, toda a escrita aqui percebida pode desmitificar negatividades em torno do mesmo Método e aparecer como legítima grande aliada de profissionais das artes e de não artistas. No caso dos atores, contribuindo para melhorar suas formas de interpretação. É congruente também para a expansão do Método FT e sua maior valorização sob as artes da cena como um todo, superando a eficácia já demonstrada nos filmes de sucesso no cinema nacional e agora a partir de experiências práticas assumidas pelo escritor. Era essencial apresentar uma relação do Método FT em novos trabalhos, por outro preparador, colocando-os como referência e material de pesquisa. Salienta-se que o uso da ferramenta na interpretação de artistas é cada vez mais importante para o sucesso de um filme. Um dos propósitos é provocar uma reflexão maior sobre a ruptura com pensamentos estereotipados na postura e relação do "ator $\mathrm{x}$ personagem".

Palavras-chave: Preparação de elenco. Fátima Toledo. Método FT. Cinema. Interpretação.

Abstracts: Through a perspective between the interpretation of actors and the languages inserted in the context of dramatic art, this article exposes the capacity of options in technical and theoretical instruments that the Fátima Toledo Method (also

\footnotetext{
*Possui graduação em Teatro pela Faculdade CAL de Artes Cênicas / PUC-Rio (2018). É formado pela Escola de Cinema Darcy Ribeiro com qualificação profissional em audiovisual (2018). Tem experiência nas artes da cena, cinema, teatro, pelos âmbitos da interpretação, direção, produção, preparação de elenco. Dispõe de habilitação legal como: ator; jornalista; modelo; contrarregra. Atua ainda em demais áreas vertentes e projetos múltiplos.
} 
called "FT Method") collaborates positively and unique, by form in most of the projects in which the preparation is found, making them peculiar. With this, all the writing here perceived can demystify negativities around the same Method and appearing as legitimate great ally of professionals of the arts and not artists. In the case of the actors, contributing to improve their ways of acting. Is congruent also for the expansion of the FT Method and its greater appreciation under the arts of the scene as a whole, surpassing the effectiveness already shown in successful films in the national cinema, and now from experiences practices assumed by the writer. It was essential to present a relation of the FT Method in new works, by another preparer, placing them as reference and research material. It is pointed out that the use of the tool in the interpretation of artists is increasingly important for the success of a film. One of the purposes is to cause a greater reflection on the rupture with stereotyped thoughts in the posture and relation of the "actor $x$ character".

Keywords: Casting Training. Fátima Toledo. FT Method. Movie. Performance. 


\section{INTRODUÇÃO}

\subsection{Dissecando o Método FT}

Fátima Toledo é a mais conhecida preparadora de elenco do país, trabalhando principalmente com o audiovisual. Ela tem um Método de interpretação para atores que divide a opinião de muitos profissionais do meio. Ao longo dos últimos trinta anos desenvolveu e aprimorou este método, do qual tem alguns referenciais a partir de exercícios de Augusto Boal ${ }^{1}$, Grotowski ${ }^{2}$ e Stanislavski ${ }^{3}$, grandes diretores e teóricos do teatro mundial. Sua proposta é um genuíno processo para atores criado por uma brasileira, algo pouco visto em um país do qual os métodos interpretativos são em sua maioria importados.

A preparadora e sua preparação adquiriram por grande parte da mídia a fama de "casca grossa". Na realidade, o que ela faz é interiorizar ao máximo o ser, para entender e chegar a níveis emocionais altos, advindos de experiências pessoais do próprio participante, as quais o mesmo pode até desconhecer.

Seu Método esteve presente em alguns dos mais conceituados filmes do Brasil e em todos se obteve o diagnóstico da grande qualidade de interpretação dos elencos, basta assistirmos: Pixote - a lei do mais fraco ${ }^{4}$; Brincando nos Campos do Senhor ${ }^{5}$; Desmundo ${ }^{6}$; Central do Brasil ${ }^{7}$; Cidade de Deus ${ }^{8}$; Cidade Baixa ${ }^{9}$, Tropa de Elite 1 e $2^{10}$, entre outros, cujo reconhecimento pela maioria dos brasileiros é espontâneo e positivo, valendo ressaltar dadas cenas marcantes.

É cabível dizer que Fátima Toledo e seu método não são específicos apenas para profissionais de atuação, mas válidos para os que nunca atuaram e/ou não são

\footnotetext{
${ }^{1}$ Foi diretor de teatro, dramaturgo e ensaísta brasileiro, uma das grandes figuras do teatro contemporâneo internacional. (1931-2009)

${ }^{2}$ Foi um diretor de teatro polaco e figura central no teatro do século $X X$, principalmente no teatro experimental e de vanguarda. (1933-1999)

${ }^{3}$ Foi um ator, diretor, pedagogo e escritor russo de grande destaque entre os séculos XIX e XX. (18631938)

4 Filme dirigido por Héctor Babenco, em 1981.

${ }^{5}$ Filme dirigido por Héctor Babenco, em 1991.

${ }^{6}$ Filme dirigido por Alain Fresnot, em 2013.

${ }^{7}$ Filme dirigido por Walter Salles, em 1998.

${ }^{8}$ Filme dirigido por Fernando Meirelles e Kátia Lund, em 2002.

${ }^{9}$ Filme dirigido por Sérgio Machado, em 2005.

${ }^{10}$ Filmes dirigidos por José Padilha, em 2007 e 2010.
} 
formados como atores. Através de sua preparação e exercícios, ela consegue extrair de uma pessoa o necessário para passar a verdade de uma cena. Ao contrário do que Stanislavski propõe em "A Preparação do Ator"11 no capítulo "Fé Cênica", Fátima não sugere ao participante do método que ele tenha apenas fé cênica nas situações que um texto possa sugerir, mas que a verdade deixe de ser mera acreditação e sim uma plena vivência. Dentre os filmes aqui citados existem muitos não atores, incluindo protagonistas, como aconteceu em "Cidade de Deus", cuja maioria do elenco não tinha experiência, mas em contrapartida já estavam inseridos pessoalmente em um ambiente semelhante ao contexto retratado nas cenas, com convivências em situações similares e/ou conhecimento proveniente de pessoas próximas sobre uma ocasião que lembra algo que o filme pretendia mostrar. Isto já deixa qualquer obra com uma realidade mais aceitável e identificável, seja para qual público for, em relação à realidade que o roteiro coloca e o cotidiano humano verídico.

No Brasil existem poucos profissionais na função de preparador de elenco para cinema. Idem quanto a locais para formação de atores exclusivamente para esta linguagem, a "sétima arte". O primeiro lugar e instituição com este intuito é justamente um centro de formação profissional idealizado por Fátima Toledo, com ênfase em seu Método, localizado em São Paulo.

É clara a repetição do uso de atores consagrados pela televisão na realização de diversos filmes. Sem dúvidas a questão do talento é levada em consideração, porém também há, além de uma estratégia mercadológica, um óbvio sinal da falta de atores com enfoque na linguagem cinematográfica em si, como expôs Vincent Cassel:

\begin{abstract}
A televisão aqui (Brasil) é tipo uma máfia. Quando tem alguém com talento, a televisão vem, pega, paga bem. As pessoas são (ficam) assim (presas). Viver só de cinema aqui é um pesadelo, eu acho. Tem poucos atores que conseguem fazer isso. Mas são muito poucos, os outros tem que fazer novela ou minissérie e eu acho que estraga a atuação, não de todos. (...) Não se tem tempo (na Tv), tem que rodar muito rápido, tem que sempre colocar uma super emoção. Nas novelas as pessoas sempre brigam, choram, o que na verdade depois não se tem mais uma sensibilidade precisa, das pequenas coisas. Não se tem em todos os lugares mil pessoas com talento, então quando tem, vamos dizer - por exemplo, vinte, trinta aqui no Rio, que vão sempre trabalhar na televisão. Então é muito triste para o cinema, para o cinema nacional. (CASSEL, 2016, não paginado)
\end{abstract}

11 Livro escrito por Stanislavski, publicado em 1936, considerado por muitos a "bíblia" da atuação moderna. 
Referindo-se ao Método FT, a cineasta Daniela Thomas fala que: "Estaríamos fazendo um cinema bem diferente não fosse por seu incrível Método." (CARDOSO, 2014, p. 241).

Sua preparação não tem como intuito e foco somente um ou dois atores integrados em uma dada obra, é necessário que o coletivo seja trabalhado, pois em um filme podem se tornar nítidas as diferenças de atuação daqueles que tiveram contato com o Método e os que não tiveram. O espectador pode não perceber o que é, mas reconhece certo estranhamento, pois os atores estão em nuances diferentes de interpretação. Fátima Toledo prioriza a criação de uma unidade ao filme. Independente que um ator tenha passado pelo processo de forma mais longa e outro de forma mais curta, estar no método, de alguma forma, é um grande passo para fazer a tal unidade se concretizar, portanto facilitando uma especial imersão para quem assistir uma obra.

O Método FT é de considerável consistência e seriedade. Sua proposta profunda de experiência permite que o ator (ou não ator) encontre uma maneira própria e autêntica para viver um personagem. Baseia-se na premissa de não dar o personagem ao ator, mas deixar o ator chegar ao personagem. Assim, o ator é ele próprio vivendo situações dos personagens. Nesse sentido se faz o título intrigante do livro redigido e co-escrito por Maurício Cardoso: "Fátima Toledo: Interpretar a Vida, Viver o Cinema"12, que apresenta e descreve o referido Método.

Toledo afirma: "O que o Método propõe é uma atenção honesta e direta com os dados da realidade, o que significa manter uma relação franca com a própria vida." (CARDOSO, 2014, p.143)

Fátima abomina ter a emoção como instrumento de seu trabalho e técnica. Embora os sentimentos e as emoções pareçam ser dois lados de uma mesma moeda, eles são assuntos muito distintos e a compreensão de suas diferenças é essencial ao método desenvolvido por ela e seu posterior sucesso.

As emoções nada mais são que reações rápidas para ameaças e/ou recompensas. Em decorrência, deixam o corpo alterado e ajudam o humano em sua

\footnotetext{
12 Livro em que Fátima Toledo narra o percurso de seleção e preparação do elenco de grandes sucessos do cinema brasileiro. Transcrito por Maurício Cardoso.
} 
sobrevivência. Reações emocionais são universalmente semelhantes em todos os seres humanos e até mesmo em outras espécies. Por exemplo, uma pessoa sorri para o seu cachorro e ele, reagindo, move o rabo. Emoções tornam-se sentimentos, são físicas e instintivas. Por serem físicas, entende-se que podem ser objetivamente medidas através do fluxo sanguíneo, da atividade cerebral ou daquilo que é de suma importância para o ator no audiovisual: as microexpressões faciais e a linguagem corporal.

Os sentimentos são, para tanto, associações mentais e reações às ditas emoções. O que os torna influenciados pelas subjetivas experiências pessoais, crenças e memórias. O preparador não precisa necessariamente saber quais são estas influências, mas vê-las como parte da formação da pessoa e contribuindo para a história de um personagem, sem que o ator force para alcançar, mas que deixe fluir como parte de uma reação natural por algo que remeteu para outro experimento original anterior, ainda que não se trate identicamente do mesmo. No trabalho de Fátima, tais reações estarão envolvidas com a história e personagem, sempre. Um sentimento é a representação mental do que está acontecendo no corpo do ator quando ele tem uma emoção e é o subproduto do que seu cérebro percebe e determina como significado para a emoção.

A Dra Sarah Mckay, neurocientista e autora de um blog sobre neurociência, complementam: "As emoções atuam no teatro do corpo. Os sentimentos atuam no teatro da mente." (HAMPTON, 2015, não paginado).

Os sentimentos são acionados por emoções e "coloridos" por pensamentos, memórias e imagens que se tornaram inconscientemente associadas com referências automáticas de uma dada emoção especial para o ator.

Fátima Toledo ressalta:

\footnotetext{
Não trabalho com a emoção, a emoção é um risco. A gente não consegue controlar a emoção, nos perdemos na emoção. E no cinema tem a questão da repetição de cenas, e a emoção tem um "rosto", ela é vinculada na vida da pessoa. Isso é arriscado. Trabalho com o sensorial, este é seguro. Ativo o Sensorial e "corto". E o ator consegue cortar, pois não está vinculado à fato nenhum da vida dessa pessoa. Para mim, a emoção é do espectador. (CIUDAD DE DIOS - Formación de Perosnajes, 2002, não paginado).
} 
Por outro lado, pode o contrário ocorrer. Como, por exemplo, o ator pensar em algo ameaçador e desencadear uma reação de medo emocional, o que é uma possibilidade concreta e prevalecer as emoções individuais, que são temporárias e em resposta a eventos específicos. Assim, pode-se concluir que os sentimentos evocados propositalmente podem persistir e se desenvolver com o tempo, reforçando a escolha feita por Fátima, que considera um risco para o ator que prioriza o preceder da emoção como suporte de uma possível verdade seguinte.

Como as emoções podem causar sentimentos subconscientes que, por sua vez, desencadeiam outras emoções e assim por diante, a vida do ator pode se tornar um ciclo interminável de emoções dolorosas e/ou confusas, que produzem sentimentos negativos, que causam ainda mais emoções negativas, onde o ator não saberá o real motivo delas, podendo afetar diretamente suas próximas interpretações cênicas, além de sua vida pessoal. Os sentimentos dependem do temperamento de uma pessoa e da aprendizagem de seu passado, variando muito de pessoa para pessoa e de situação para situação.

As emoções e sentimentos desempenham um papel importante na maneira como o ator experimenta e interage com o mundo, porque trata-se da força motriz por trás da maioria de seus comportamentos pessoais, úteis e inúteis e transpõe isso em ações durante o fazer de seu ofício.

Não é exagero dizer que existe um cinema com e sem Fátima Toledo, o que a torna, bem como seu método, algo para um maior aprofundamento e valor, como através de um artigo, para que haja maiores entendimentos, utilizações e reflexos da tendência positiva de seu trabalho, sendo que com experimentações em outros e novos elencos.

Marília Pêra ${ }^{13}$ pontua: "Quando vejo um filme brasileiro e percebo grandes interpretações, tocantes emoções e o respeito a pausas que são semelhantes às dos seres humanos, sei que ali há um trabalho de Fátima." (CARDOSO, 2014, p.47)

Para a qualidade de uma interpretação a partir da preparação, basicamente é necessário apenas gente disponível para ver, ouvir, sentir e transmitir.

\footnotetext{
${ }^{13}$ Foi uma importante atriz do teatro, cinema e televisão. (1943-2015)
} 
1.2 Análises etnográficas sobre a preparação de atores para cinema em projetos de curta duração e com elencos principiantes, tendo elementos referenciais do Método Fátima Toledo

Analisando etnograficamente intérpretes para atuarem em curtas-metragens e afins, é percebido que os atores em sua totalidade ou maioria tinham poucas experiências com o trabalho direto de um preparador de elenco e até mesmo como atores em uma obra artística ao teor cinematográfico e audiovisual. As percepções que são apresentadas neste trabalho provêm de uma junção de fatores, pois ao mesmo tempo que o autor atuava como preparador de elenco, também fazia o estudo dos casos com intuito acadêmico-investigativo, tendo por base as atividades profissionais que ocorriam.

As preparações tiveram como referência principal os métodos e exercícios que Fátima costuma usar, entretanto não necessariamente idênticos, ou seja, não se trata de uma réplica exata das técnicas originais utilizadas por Fátima, mas apenas uma alusão às mesmas. $O$ processo de preparação de elenco para cinema em sua enorme quantidade se dá principalmente para filmes longas-metragens e dificilmente para curtas. As atividades foram feitas no segundo semestre de 2017 até julho de 2018, a partir de filmes realizados como conclusão de curso em uma escola cinematográfica no Rio de Janeiro.

Muitos profissionais das artes cênicas, do cinema e ainda de outras áreas se perguntam erroneamente: "Mas fazer preparação para curtas-metragens? Pra quê?". Nota-se, assim, que dão um foco e necessidade minimizada ao trabalho da preparação de elenco para projetos de curta duração ou que a princípio requerem menor participação dos atores. Mas tal necessidade de ter esta função como parte de um curta vem justamente por estarmos em um país onde os diretores cinematográficos possuem pouquíssima afinidade e formação com a direção de atores. Na Escola de Cinema Darcy Ribeiro, exemplificando, há uma estrutura base, essencial para todos os âmbitos que um diretor precisa ter conhecimento e prática, mas a valorização da especificidade da relação diretor $x$ elenco se dá muito brevemente. O que não é um erro das instituições, mas de toda uma visão de valor anterior que fora empregada para a direção de atores no país há anos e que persiste, seja pedagogicamente ou profissionalmente. 
Contudo, a preparação de elenco se faz primordial na medida em que os atores também têm, na maior parte das vezes, a inexperiência nestas funções e não se conhecem, porém seus objetivos primários são de tocarem a emoção do público com suas performances, sob uma verdade, ou seja, com o máximo de natureza possível. Principalmente se considerarmos que estamos em um período que a interpretação contemporânea tem um telespectador cada vez mais crítico, tendente a negar aquilo que vai além da realidade próxima cotidiana (ou possivelmente próxima) e que é mais adepto ao que Ihes convence com melhor facilidade, rapidez.

$\mathrm{O}$ ator deve agir como se não estivesse sendo um personagem, mas ser. Este é o fundamento que rege o Método de Fátima Toledo para ter uma maior credibilidade perante o público e principalmente para dar uma qualidade de trabalho dos atores em forma da unidade já citada.

A maioria das colocações de práticas cênicas para a preparação sob investigação científica serviu por igual para as atividades na completude dos elencos e não apenas em um só trabalho audiovisual, mas de todos os que foram feitos pela dita instituição de cinema e sempre com o mesmo preparador / observador / autor, que fez uma coleta de dados prévia sobre os parâmetros realizados por Fátima Toledo e como os adaptar, para aplicá-los de forma independente, responsável e sadia. As obras são: Écharpe Noir - direção: Barbara Fuentes; Imersão - direção: Alexandra Alves; Sobre Ratos e Café - direção: Márcio Paixão; Segundo Encontro - direção: Tainá Ramos; Submergir - direção: Márcio Paixão, e o videoclipe musical de rap, Catarse - direção: Igor Freinas e Alessandra Merat.

\section{EFEITOS}

\section{1 Écharpe Noir}

Em um primeiro momento ocorreu a preparação no curta Écharpe Noir ${ }^{14}$, onde os atores não eram profissionais em suas funções, mas dançarinos e não se conheciam diretamente. A partir da iniciação na preparação, foi proposto um contato diferente dos corpos em si, mas trabalhando este quesito de forma isolada, até porque

\footnotetext{
14 Filme dirigido por Barbara Fuentes, 2018.
} 
os sujeitos já se conectariam facilmente por serem dançarinos. Optou-se por uma forma abrangente, visando criar uma relação menos óbvia, cuja conexão entre ambos fosse além do corpo, promovendo um estado de presença concreto e maximizada no momento da cena com suas significações, antes da troca afetiva entre corpos. $\mathrm{Na}$ trama eles fizeram um casal que se distancia por conta de uma viagem.

Ao decorrer da preparação, sem toque os atores foram se exercitando a partir de comandos que pudessem ativar a paixão, a dor, suas ancestralidades e a conectividade permanente, questões fortes no filme.

Entre as outras atividades, estava ainda o Exercício do Espelho (em alguns locais é uma base de iniciação ao fazer cênico), em que um se espelha no outro para fazerem simultâneos e similares movimentos, de acordo com o que cada um fazia e como aquilo era refletido entre eles. Existiam pausas para que a conexão primeira se desse somente pelo olhar por um longo período. Os atores se mostraram com disposição do início ao fim, entretanto, por inúmeras vezes, era perceptível que não entendiam muito do que estavam fazendo e a real motivação sobre para que lugar aquilo os levaria. Generalizando, era uma espécie de descoberta para todos, para o preparador, pois começava em uma função nova, apesar de ser ator, e para os atores do filme, pois realizavam atividades que não eram acostumados a fazer, apesar de serem dançarinos.

Os exercícios foram se intensificando conforme era percebido o aumento da afinidade entre a dupla trabalhada. Foram incrementadas situações por meio de dinâmicas com a respiração de cada um, sendo estas equalizadas com sugestões e mediações das porcentagens - de cinco até cem por cento. Tais respirações recebiam nomes, de acordo com a respiração de um tipo de sensação emotiva específica em um ser humano, com a pretensão de ser despertada em sua essência orgânica.

Por respeito e delicadeza que trata, esse exercício lembra o "Rasa-Boxes", mas não se trata exatamente desta técnica, apesar de tê-la como maior influência. $\mathrm{A}$ prática se identifica bastante com a "Bioenergética", que Fátima costuma usar. Os atores alcançavam o ápice de cada sensação em toda porcentagem proposta, eles viviam. Foram realizados ainda exercícios da "Técnica Meisner", que envolvem repetições entre a opinião positiva sobre dada coisa e a contrária, sobre a mesma coisa. Sem acrescentar nada ao texto e a "coisa" proposta, apenas no embate entre 
a defesa de opiniões de cada, o que alimenta os atores para uma organicidade de reações conforme as repetições são feitas.

A utilização com os textos do roteiro de cada obra, ocorreram por último, quando a unidade de atuação já era vista presente entre todos.

O realizador fílmico Walter Salles afirmou em depoimento:

[...] não acho que exista um só caminho para a preparação de atores de um filme. [...] De todas as escolas de interpretação, a que eu sempre me senti mais próximo foi aquela desenvolvida por Sanford Meisner, um ator e diretor que abandonou o Actors Studio para criar um modelo próprio de interpretação. O método de Fátima não fica atrás em originalidade. (CARDOSO, 2014, p. 131)

Em todos os momentos em que a emoção (sobretudo de modo dramático), com choro natural vinha nos atores, eles pediam para parar. Pelo fato de não terem tanta experiência com atuação, estes pedidos foram identificados como algo provindo da pessoa e não do ator em obra já em exercício com o seu personagem. Como qualquer ser humano, os atores possuem mecanismos de emoções e sensações, que dependendo da situação e quantidade querem bloqueá-los de forma assintomática (ou não), por conta de lembranças e experiências de sua vida pessoal. O distanciamento disto, que não é igual ao Brechtiano ${ }^{15}$, é o maior desafio seja ao preparador, como ao elenco. O que se torna uma questão para ser resolvida é a do ator ficar instigado e convencido de que a preparação é para e do ator-personagem apenas, de forma que o público não possa perceber toda a história corporal e mental que aquele sujeito tem, pois ela não foi exposta, mas utilizada através de ferramentas individuais para o ficcional. Ao mesmo tempo em que a vida pessoal do ator não interessa para o preparador, ela tem a possibilidade de se tornar alvo de barreira.

A melhor opção vista foi a de realizar algo já pontuado, ou seja, para que os atores não realizassem o "SE mágico" que Stanislavski sugere: "se eu fosse", "se eu estivesse" e vertentes. Foi promovido o reverso, o que Fátima prega como máxima, eliminar as possibilidades do "se", ou seja, que os atores não se colocassem no lugar como uma alternativa possível, entretanto para que eles agissem sendo, que estejam

\footnotetext{
15 Sobre a técnica teatral desenvolvida por Bertolt Brecht (1898-1956) que, entre outras coisas, faz uso de uma exposição dialética, clara e inteligível e que procura obter da plateia uma atitude crítica em relação aos fatos encenados, um distanciamento emocional.
} 
concretamente, se definirem como tal e somente, o "eu sou", obtendo a propriedade sentida no imediatismo ou na mais curta proximidade de tempo, e depois a eliminar de forma energética, já que é irreal aquilo que o ator se apropriou. Assim sendo, ao interpretar deve-se ter a consciência de que o ato é uma circunstância imaginária, mas naquele momento ele vive tal utopia.

Um dos receios da preparação de elenco é desta ser considerada como invasiva e/ou de diminuir a autonomia funcional e criativa, tanto para os diretores das obras, como para os atores. Mas acabou por não ser. Ao final desta e de todas as outras preparações, foi visível a mudança positiva nos corpos e no pensar da maioria dos seres artísticos que se envolveram, sem prejudicar a função individual que the foram destinadas. Segundo alguns dos participantes, dificilmente a afinidade e a verdade de suas atuações seriam construídas de modo tão consistente, ainda mais pelo pequeno período que fora realizada, o que consideraram surpreendentes.

A verificação final sobre este primeiro contato realizado de preparação pelo autor do presente material textual, se beneficiando de referências do Método de Fátima Toledo, é de que os atores para fazerem com verdade devem ter, antes de tudo, disposição. E quanto mais verdade estiverem em um trabalho, seja com duração de trinta segundos ou de quinze minutos, a autenticidade será deduzida pelo espectador com algum diferencial e pontualidade boa, mas que possivelmente não poderá dizer do que se trata. A verdade, mais do que nunca, é palavra-chave para a boa competência do cinema nos dias de hoje e quiçá já colocando na póscontemporaneidade.

\subsection{Sobre ratos e café}

Em Sobre Ratos e Café ${ }^{16}$ a preparação foi realizada com três atores do filme. Uma menina/criança, uma mulher adulta e um homem. Todos faziam parte de um mesmo núcleo familiar ficcional, o qual era conturbado. Trabalhar com crianças é sempre algo delicado, mais ainda se tratando da seriedade da interpretação naturalista para o ficcional. No começo do processo foi realizado uma conversa entre

\footnotetext{
${ }^{16}$ Filme dirigido por Márcio Paixão, 2017.
} 
as atrizes que interpretariam "mãe" e "filha", a menina ("filha") parecia estar alheia e não se importando tanto com a atividade, a mulher (mãe), por sua vez, demonstrava mais interesse, até porque era alguém mais madura na área.

Logo após, foram dadas certas opções de respiração, moderadas e com ambas abraçadas, novamente o desinteresse da criança se fazia nítido. Porém ao conversar com a mãe verídica ficou muito compreendido que a menina atuava mais por vontade e pressão desta sua mãe e não tanto por vontade própria. Ou seja, talvez por um sonho interno e antigo que a mãe não realizou e passa como expectativa para a menina fazer. Depois, em conversa isolada com a criança, perguntando se ela particularmente realmente gostaria de fazer, ela disse que sim, mas novamente ficou um contraponto, estando explícita sua não vontade fixa para estar enquanto atriz naquele projeto.

O diretor também estava a par e foi conversar com ambas, a Mãe e sua Filha, as reais, não personagens, sobre se elas levariam adiante suas participações, e disseram que sim. Ainda que tenham tido estas opiniões, o diretor não gostaria de manter a menina no projeto, justamente pela explanação e sentimento que teve, de que ela não estava fazendo aquilo por vontade própria. Contudo, com a afirmação de ambas e com o pouco prazo para se filmar, o diretor decidiu aderir à opinião delas e foi contrário com a sua própria visão, que era a mesma do preparador. Pelo set, na última cena da ordem de filmagem, um mesmo take fora repetido em média de nove vezes, o que para o cinema é algo comum, mas ali foi o ápice para ter a certeza da contrariedade e falta de ânsia da menina. Fátima Toledo em muitos de seus filmes, como "Pixote: A Lei do Mais Fraco ${ }^{17 "}$ ", trabalhou com diversas crianças e sempre teve esse cuidado, em relação a quem realmente queria ou não.

Toda a situação envolvendo as personagens da menina e sua mãe tiveram como resultado uma preparação pouco participativa e isso é o reflexo de como a preparação de elenco depende intrinsecamente da predisposição e entrega dos atores envolvidos, se tratando de crianças essa importância se reforça. No caso, também em relação ao homem (ator que seria o "Pai" no filme), o trabalho não se fez a contento, pois se tratava de um ator experiente que, de certa forma, desdenhou do valor da preparação

17 Filme dirigido por Hector Babenco, 1980. 
para aquele curta-metragem, seja pela tal experiência que o mesmo já tinha, pela duração do projeto, ou até possivelmente pela faixa etária do preparador, jovem se comparado com a idade do ator. De novo, dependeu da disposição de quem estava relacionado artisticamente. Estar neste projeto foi a certeza de que a preparação não pode ser imposta e só ocorre, antes de tudo, por livre e espontânea vontade dos atores.

Segundo Fátima Toledo: "A única coisa que impede o ator de trabalhar é sua indisposição de estar verdadeiramente presente, despojando-se de ideias prontas e colocando seu corpo e sensações a serviço do filme." (CARDOSO, 2014, p.157)

\subsection{Imersão}

Em Imersão ${ }^{18}$ a preparação do elenco foi feita com dois atores. Se tratava de um filme que exigia um vigor psicológico muito grande dos atores. Existiam cenas de estupro entres os personagens, que tinham uma relação de casal na ficção. Os atores eram profissionais, não se conheciam, mas pessoalmente já estavam com uma afinidade amigável, que era de valia para seus vínculos cênicos. Durante a preparação, foram feitos exercícios de contrariedade e polos opostos entre os dois e, depois, foram sendo intensificados com falas entre eles. Não se usaram personagens, eram os atores em situações criadas pelo preparador. Em dado momento, o ator que fez o "Marido" criou um limite entre até onde poderia ir, em termos de palavras. Quando já estava em um clima de jogo cênico intenso, ele saía do jogar e mostravase apenas como pessoa fora de uma proposta cênica. Aquilo era o Ator com medo de si mesmo, de embarcar no "Eu" único.

O Método de Fátima, condensando e ligando ao que ele espera do ator, nada mais é do que justamente uma entrega no próprio eu, um mergulho em si mesmo. Cada humano acha que se conhece veementemente, mas em nosso sistema cerebral o inconsciente cria impedimentos de modo automático, provindo de situações que aquela pessoa já tenha passado e aquilo então lhe causará alguma sensação que o marcou, como um trauma. Todavia ao estar em outra e nova situação, que dá a

\footnotetext{
${ }^{18}$ Filme dirigido por Alexandra Alves, 2017.
} 
sensação parecida, uma espécie de alerta acontece no ser, devido suas memórias e sensações ocultas. Pelo pouco tempo que se tinha para preparação, não foi possível trabalhar mais para ver se ele (o Ator) ultrapassaria suas próprias barreiras ou não. Assim, foi respeitado o patamar que ele gostaria de ir. Este escolheu o que foi conveniente na preparação e nas suas percepções para aplicar durante as filmagens. Ainda durante a preparação, em outra atividade, o ator entrou em um determinado transe por subações que pareciam ir para além da associação de casal dado aos personagens, ele tirou a roupa, mas não fez ação alguma e nem propôs nada a partir disso para com sua parceira de cena.

De todo modo, pelo filme ter uma cena de estupro, aquilo foi obtido em análise posterior pela preparação como algo não pré-determinado pelo ator, mas sim por ele já estar dentro do enredo, linha dramática e de acontecimentos que o seu personagem passaria, além de participar dos exercícios antes. Ou seja, uma ação não concreta da dramaturgia que fariam nas filmagens, mas que remetesse. Embora o ator não estivesse exatamente com disponibilidade total nos exercícios, esta sua atitude incorporou um nível de acreditação na relação entre os envolvidos, nos espaços e a postura de ator, como algo não tão previamente pensado, mas involuntário, porém ressaltando que o mesmo conseguia separar seus limites conscientemente. Atividades de preparação já diretas que envolvem o tema de uma obra podem fazer com que se tenham outra imagem para além. No contexto citado, podendo significar um entrelaçar adentro do que viria e estava no roteiro individual a ser seguido.

A reação da atriz (que interpretou a "Esposa") foi de compreensão, mas ela não se deixou fazer o mesmo, não quis também tirar a roupa, pois entendeu que sua personagem não teria um ato de concordância em relação ao ocorrido, leia-se: que não seria permitido por sua vontade. Ao expor isto, o Ator se deu conta pessoalmente e ficou envergonhado do que tinha feito, porém a atriz disse que compreendeu, ficou feliz pelo ator ter percebido a situação constrangedora e mais pela sua consciência de até onde deveria prosseguir depois de seu dado ato inicial. Julgou válida no momento apenas para ele. Pois além disso, qualquer atitude sua maior (do ator), poderia passar para ação abusiva ilegal, da qual o preparador a partir da primeira suspeita já interromperia todo o processo, mesmo que a intenção do ator se desse de 
modo "profissional", sendo que não tendo combinação / contrapartida de sua parceira cênica, seria crime de modo injustificado.

Nota-se o ocorrido no filme "O Último Tango em Paris ${ }^{19 ", ~ o n d e ~ a ~ l i n h a ~ d a ~}$ liberdade, libertinagem e consenso se ultrapassaram em pré-acordos e indicações supostas entre demandas e acertos do diretor e ator, ocorrendo ações extras, graves, de infortúnio sexual, das qual só a atriz envolvida não estava ciente da cena como um todo. Isso demonstra o quanto também uma supervisão da preparação é importante para designar linhas e separações pertinentes, de modo que se tenha domínio de até que ponto a cena é moral e ética humanamente e a critério dos atores, antes dos personagens.

Voltando para a obra "Imersão", reitera-se que durante todo desenvolvimento do projeto, a atriz mostrou realizar a preparação de modo extremamente interiorizado. Talvez uma escolha pessoal para a construção de seus personagens, porque suas próprias ações nos ensaios e nas filmagens tinham um trajeto próprio de dramaturgia para cada ação e a junção que fez disso com a preparação resultou em uma força especial na cena.

Fátima complementa: "Não é preciso interferir na vida ou história de ninguém para fazer a pessoa entrar na situação exigida pela cena e pelo projeto do filme". (CARDOSO, 2014, p.157)

\subsection{Segundo encontro}

No curta-metragem Segundo Encontro ${ }^{20}$ o preparador foi convidado em um período antecipado pela diretora para fazer parte do projeto, sendo que este filme teria como protagonista uma atriz selecionada, mas por fim a própria diretora decidiu ser a atriz. O roteiro trata-se de um relacionamento casual heterossexual e étnico-racial igualitário entre negros, mas que ainda sim ocorria preconceito.

A preparação de Fátima Toledo não compactua com a atuação por formas marcadas, engessadas. Se a verdade for e tiver empregada para cada momento de

\footnotetext{
19 Filme dirigido por Bernardo Bertolucci, em 1972.

20 Filme dirigido por Tainá Ramos, 2018.
} 
troca afetiva, aquela ocasião sempre será única, mesmo que haja repetições para se gravar uma cena. Com o ator desta obra, o "homem do casal", durante o desenvolvimento da preparação foi realizado variados exercícios e, na maioria deles, ele se entregava enquanto ator isoladamente, mas não enquanto pessoa em um ofício. São coisas diferentes. E era obtido um resultado formatado, "mascarado", o que faz esconder a pessoa em sua essência. A atriz/diretora, que ao contrário do ator não era atriz profissional, notou e tentava ajudar durante as passagens de jogos cênicos entre eles. Até que chegou o dia das filmagens e ela percebia que a atuação do ator convencia um público geral, mas ainda não se fazia suficiente, pois observava que não havia uma verdade totalmente condizente.

Essa verdade é aquele ponto em que o telespectador percebe que há uma coisa distinta na interpretação, que o prende, quase inexplicável. A atriz, por ser a primeira vez dela na função, inicialmente se entregou, mas quando algum exercício tocava em algo pessoal ou que a remetia alguma lembrança, ela pausava, bloqueavase para conectar com suas verdades, as mesmas que possivelmente tem agregação em sua interpretação para uma ficção. Nesta situação, o preparador não pode e não deve obrigar e nem insistir demasiadamente, apenas respeitar. No geral, ficou factualmente provado que a eficácia da preparação só acontece se as pessoas estiverem disponíveis antes do ator - antecedendo o personagem. Fátima diz: "preparador apenas orienta, conduz o ator a sua descoberta, mas a atuação é dele. Se ele não traz nada de novo e genuíno é porque não pode oferecer, se traz é porque descobriu e se revelou em cena". (CARDOSO, 2014, p. 158).

\subsection{Submergir}

O filme Submergir ${ }^{21}$ foi um projeto realizado em vinte e quatro horas e tinha que ser feito desta maneira, pois era requisito de um festival de cinema específico. Então a preparação também foi realizada apenas e durante este breve período. $\mathrm{O}$ curta é sobre um relacionamento homo afetivo entre homens e com distanciamento de moradia entre o casal, até que se reencontram, porém há a notícia de que um dos

\footnotetext{
${ }^{21}$ Filme dirigido por Márcio Paixão, 2017.
} 
rapazes está com HIV. A preparação foi realizada na praia, local onde noventa por cento das filmagens ocorreram. Os atores estavam entregues e em plena disposição. Durante a madrugada foram feitos Exercícios de Desestabilização para o elenco, em outras palavras: em via do roteiro que eles já haviam se apropriado, um pouco antes das filmagens era proposto algo que parecia ser apenas um treino ("passagem") de uma cena. Então o preparador pedia para só um dos atores, em sigilo, mudar alguma parte, ou palavra específica, assim automaticamente desestabilizaria o outro ator e estes então deveriam jogar a partir daquela novidade ao enredo. Sobre este peculiar exercício, Fátima Toledo diz:

Incorporei ao Método este procedimento que me permite desconstruir os artifícios da pessoa, para que ela possa estar inteira no filme e para que esteja aberta para o inesperado. Desde o "O Céu de Suely" tenho utilizado muito isso, especialmente em cenas que envolvem reações físicas de amor ou de ódio, por exemplo, transformando um tapa num beijo ou vice-versa. (CARDOSO, 2014, p. 183)

Em via disto, a utilização dessa atividade foi extremamente levada em consideração pelo preparador de "Submergir", na importância de que se tratava de uma história envolvendo uma forte relação de amor e uma intensa revelação que poderia abalar tal relação sentimental. Os atores foram entendendo sem precisarem de mais explicações daquele que os preparava e, no momento da filmagem, puderam passar exatamente e precisamente a nuance sútil que a cena precisava.

\subsection{Catarse}

Já para o clipe musical de rap Catarse ${ }^{22}$, a utilização da preparação aconteceu acrescentada de uma espécie de auxílio na direção dos atores, devido o chamamento feito pelo diretor ao preparador ter sido efetuado praticamente na mesma data da filmagem. A composição da música que o clipe representaria serviu como roteiro também. Tinha forte viés social e político, dizia sobre as desigualdades perante as variedades de perfis do povo, tendo críticas aprazíveis para um determinado governo que não faz uma boa administração e este como o grande culpado das mazelas na

22 Videoclipe dirigido por Igor Freinas e Alessandra Merat, 2018. 
sociedade atual. As pessoas utilizadas não eram atores profissionais e o intuito do diretor era de passá-las apenas como um registro de documento, entende-se por pessoas que tem "voz ativa", agindo normalmente com a base do roteiro. Um dos participantes acabou realizando o contrário. Talvez por ser um projeto em que a finalidade é artística, isto tenha influenciado para ele agir representando e não apenas agindo com naturalidade pessoal, sem mais e menos, de somente falar determinadas palavras para a câmera como si, por um registro documentado.

Ficou algo formado e superficial cada take feito com ele. Para tanto, como o preparador estava acompanhando a filmagem, teve a liberdade concedida para intervir e assim foi feito. O preparador passou a contracenar com o participante, dando uma ótica maior para o que se queria de cena e ativando energias presas no íntimo do ator que estava "na caixa", já que ocorriam formatos de ser algo além do que é. Era necessário "quebra a caixa" posta. Por fim, depois disso, o tal participante do clipe passou a contracenar com a câmera e a tendo como seu diálogo, dando os gritos que estavam ocultos internamente, necessários. Essa atitude ficou, ao ver da direção, coesa, como uma representação de um povo, colocando assim que o poder maior vem do cidadão, antes de qualquer poder instaurado. Foi percebida uma beleza excepcional nos olhos do participante, que passaram a lacrimejar como um sinal de certa raiva pessoal, da qual não estava sendo vista antes, ele estava definitivamente sentindo. E não atuando.

Por vezes o trabalho da preparação de atores seguindo o Método FT se torna válido que o preparador se coloque na situação, mas apenas com o intuito de apoiar, isto deve ser muito evitado e diretamente nas filmagens. Na medida de qualquer exceção, tem de fazer com extrema sabedoria e cautela. Fátima Toledo acrescenta algo que se relaciona: "Como o Método conduz as pessoas para a verdade, ele cria condições para que apareçam os aspectos sombrios que raramente vivenciamos ou encaramos frente a frente." (CARDOSO, 2014, p. 143).

\section{FÁTIMA TOLEDO E UM ADENDO SOBRE O SEU MÉTODO NA TELEVISÃO}

As maiorias dos trabalhos audiovisuais em que Fátima Toledo participou foram feitos para o Cinema. Porém, com o passar dos anos as produções televisivas 
começaram a perceber um pouco mais da eficácia de seu Método, como feita a incorporação em "Felizes para Sempre"23. Além do que, pela prejudicial repetição no uso de atores em produções televisivas ocorrerem equivocadamente de modo frequente. ressalta:

Boni, um dos homens responsáveis pelo "padrão Globo de qualidade"

[...] nunca admitimos esse conflito. O controle ia além, evitando tramas e personagens parecidos em cada produção. A liberação total para uso de artistas em diferentes papéis ao mesmo tempo e mesmo para trabalhos seguidos é seguramente a canibalização do elenco. (PEREIRA JR., 2014, não paginado)

Há também outra repetição, a escolha dos atores para um tipo de interpretação naturalista, apenas. Com isso, inevitavelmente a inclusão do trabalho da preparação de elenco foi tornando-se cada vez mais repensada, se precisava, para evitar o cansaço do público, que é exigente e nem um pouco ignorante, diga-se: sabe opinar mais do que ninguém, sobretudo na proveniência de um país como o Brasil, que é o maior produtor de telenovelas e tem os maiores índices de audiência mundial, tendo-as como o produto audiovisual mais visto pela nação. A preparação nas novelas com o Método FT é algo de uma impossibilidade praticamente total de acontecer, porque se tratam de "obras abertas", onde a linha dramatúrgica e as curvas dramáticas dos personagens podem mudar a qualquer momento, de acordo com as preferências e reações do público. Fátima ou discípulos de seu Método acabariam por ter que acompanhar o fluxo da obra de forma completa, do início ao fim, o que torna o trabalho de divisões de "unidades" do ator mais difícil, pois a obra também deixa se tornar unidade, na medida em que não está "fechada" e sua escrita altera-se constantemente. Com isso o ator, na realidade, se descobre ao longo do processo. Vale colocar que acontece outras formas de preparação, mas não pelo Método de Fátima.

A preparação do elenco de uma novela costuma ser e é mais recomendada fazê-la antes das gravações, para servir de base principal ao eixo do personagem e ele ir se moldando a partir do que fora dado nos ensaios antecipados. Contudo, de um

${ }^{23}$ Série exibida pela TV Globo, 2015. 
tempo para cá, não ignoram esta opção no todo. Passaram a adotar o uso daquilo que não chamam de "preparador", mas de "coach" (do inglês: treinador; instrutor), que faz um trabalho parecido como se entende o de preparador, porém com um foco mais individualizado em cada ator / personagem, de acordo como reagem os telespectadores ao decorrer e das probabilidade de mudanças pelo autor.

O diálogo televisivo é rápido, um bate-bola cotidiano onde as diversas tramas se interligam, mas é ainda são bastante distantes do intimismo e do relacionamento interpessoal seleto que só a linguagem cinematográfica é capaz de causar. Geralmente quando a televisão decide por usar preparadores de elenco influentes no cinema, as obras realizadas entram em um viés do qual se vê juntamente um projeto em seu todo diferenciado ao colocado propriamente nas novelas, tendo certas utilizações e decisões nitidamente cinematográficas, em planos, câmeras, lentes e claro a intimidade de cada ator exposta mais delicadamente. Na maior parte das vezes quando isso acontece, se dá em séries e/ou minisséries.

Assim os produtores e diretores têm noção suficiente de que o público vai perceber uma linguagem artística e técnica mais próxima do cinema, para tanto se faz necessário que a interpretação dos atores esteja além de um panorama cotidiano que aproxima o personagem da telenovela. Ou seja, não creditando como um simulacro de um amigo de quem o assiste, entretanto do público como parte intrínseca de quem o acompanha, uma espécie de espião.

$O$ ator no Brasil geralmente preza por uma atuação aonde seu trabalho seja feito de modo que cada obra é uma, então que a diferenciação na atuação possa ser percebida de uma forma igualmente única entre estas, uma experimentação. Entretanto a probabilidade para que isso ocorra na televisão não é alta. Por conta da rapidez e a prontidão constante da qual o ator fica submetido, além do desgaste físico e emocional causado por uma obra como a telenovela, que varia de sete, oito, dez ou mais meses de gravações / no ar, um tipo de gestação que somente no último capítulo o público consegue fazer uma definição sobre quem era o personagem.

O gênero novela possui uma dramaturgia que em grande parte das ocasiões não tem compromisso exato com a realidade. A interpretação dos atores pode ser naturalista, porém, quando o texto tem questões supostamente não convencionais, a dada interpretação tem o desafio de através disso ultrapassar um mero naturalismo 
interpretativo. Com mais este ponto, o Método FT caracteriza-se como uma opção que deve ser mais pautada, refletida, significada por aqueles que estão relacionados e na responsabilidade da atuação para a televisão, seja pelos atores, como pelos diretores artísticos e gerais. Reestruturar um Método que prioriza que o ator não represente, mas viva, se aplica em uma avaliação de como isso seria feito por um longo tempo e tendo oscilações da linha de ação e dramatúrgica do personagem, o que pode ser arriscado e mais desgastante para o ator e sua pessoa.

Dito isto e que não são todos os atores profissionais que gostam ou aderem ao Método, por propósitos e ideologias pessoais, a metodologia aplicada por Fátima Toledo que prega ser usada na coletividade, para chegar na unidade, poderia ser um meio ao ter adaptação pelos ditos "coaches", preparadores de qualquer emissora televisiva, como parte da parceria entre atores, sugerindo além do trabalho que já seria realizado previamente. O Método FT agregaria todos as partes e com o provável resultado de uma qualidade interpretativa maior, na conjuntura dessa busca por avanços individuais de seu personagem e credibilidade junto da crítica popular e especializada. Os trabalhos artísticos poderiam ter uma realidade e um diferencial de grandeza à parte, em cada momento das cenas exigidas.

Tendo esses discorrimentos, é válido relacionar com a importante diferenciação feita em um trecho da obra Le Comedién désincarné24 ${ }^{4}$ do francês Louis Jouvet 25: "O 'acteur' só pode desempenhar certos papéis; distorce os outros de acordo com sua personalidade. O 'comédien' pode desempenhar todos os papéis." (JOUVET, 1938 apud MARCADÉ, 2018, p. 49, tradução nossa) ${ }^{26}$.

Em questão, compreende-se que não é um "ator" que adapta o personagem ao seu perfil, mas ele que tem que se adaptar e quando isso acontece será "comédien". Ou seja, ele imaginará e criará a partir de uma realidade extra, onde possui consciência de que vai se desvincular totalmente no momento que não estiver mais em cena. É de se observar que na França, local originário da nomeação "comédien", esta palavra não equivale somente para algo relacionado ao cômico, ator

\footnotetext{
${ }^{24}$ Livro publicado em 1943, aonde Louis Jouvet realiza reflexões desnudas, seus modelos, suas influências literárias e filosóficas, seus métodos de trabalho artísticos.

${ }^{25}$ Foi um ator francês, diretor e diretor de teatro. (1887-1951)

${ }^{26}$ Trabalho de conclusão de curso escrito e publicado por Émilie Marcadé em 2018, sobre: "Diferenças na prática de atuação, em criações de ficção, dependendo da cena e da tela".
} 
de comédia e humor, porém se trata de uma definição mais complexa, indo a mais do que pode soar aos brasileiros, de acordo com a etimologia da palavra e sonoridade causada. O "comédien" é um ator mais completo, segundo compreende-se da explicação dada por Louis Jouvet. O "comédien" não vive em certo comodismo de sua interpretação naturalista a partir do perfilamento do "eu".

Pelas novelas, onde geralmente as obras são inéditas, isto faz com que a ideia do público de uma "atuação repetida" aconteça mais facilmente. Na televisão brasileira, que tem altos números de obras abertas, a segunda opção seria mais viável, de estar / ser "comédien"; o processo de descoberta e criativo pode transpassar as limitações de quais escolhas e pensamentos tidos sobre como se encontraria o personagem, não o pré-determinando de acordo com possibilidades. Em outras palavras, equalizar o "eu sou" proposto por Fátima junto de todas as novidades que venham a aparecer nas evoluções por capítulos futuros.

Isto é, se dados instintos vierem ao natural, preferenciar o incremento disso é útil demais. Pois seria algo diretamente sincero da formação pessoal do ator que estaria sendo agregado para seu personagem.

Seria incabível deixar de notar outra relevância no que se atrela entre televisão e atores: a questão de que a beleza estética, subjetivas - mas com padrões instaurados pela indústria capitalista, influencia para as seleções dos elencos. Afinal, se tratam majoritariamente de obras que dependem de suas relações comerciais. $\mathrm{O}$ nome "comercial", que é o intervalo como pausa do que está sendo exibido não é à toa, ali são oferecimentos daqueles que patrocinam os programas que são parte da grade do canal e estão sob exibição. Internamente, nas emissoras, costuma-se chamar as obras e tipagens de entretenimento de "produtos". Com isso, o talento do ator tem muita chance de ser levado em segundo plano e é capaz de ocorrer uma comodidade por parte deste, na sua interpretação, o que é perigoso, afinal ele estará ganhando (além dos ganhos externos publicitários, promocionais) e isso pode dar um ideário de suficiência. Além disso, por rostos bonitos chamarem atenção, junto do glamour que a fama causa ao público, há de se atentar ao fato dos avanços das redes sociais que colaboram para a credibilidade do ator e que podem levantar suas probabilidades de presença em elenco, de acordo com a quantidade que tenha de fãs, seguidores. O que leva para mais um motivo da referida repetição de atores, fazendo 
com o passar do tempo que seja mais do que uma normalizada repetição por escalação do elenco, mas transformando-se em um acúmulo e falta de tempo suficiente para o ator descansar sua imagem, assim como se reciclar enquanto artista, tornando a estática de seu modo de atuação igualmente repetitiva.

A atriz Bete Mendes argumenta:

[...] a beleza é um parâmetro muito perigoso. [...] tive dificuldades graves com colegas que não sabiam sequer qual era o assunto da cena. Eu prefiro contracenar com uma parede do que com uma pessoa se o olho dela está vazio. É uma displicência com a profissão, que é honrada e bonita. Tem gente que diz: 'Ah, é que ontem tive uma festa'. Digo: 'Teve? Eu também gostaria de ter tido'. (MENDES, 2012, não paginado)

O comprometimento do ator com sua profissão pode ser visto como duvidoso, pois todas as ilusões que a grande exposição para milhões de pessoas pode causar afetam diretamente o comportamento dele. Uma preparação de elenco assertiva pode ser uma ajuda crucial em cada projeto envolvido, entre os níveis ator x personagem.

Uma armadilha é feita ao ator que se encontra na televisão, porque geralmente transcorre uma ilusão de que é um veículo midiático fácil de lidar, e não é. Pela tal alta exposição de imagem, o talento individual pode ser coberto de: apenas ser um rosto conhecido que venha a acarretar um protótipo de vendas, como um Modelo; isto pode vir a acontecer de modo imperceptível pelo artista, porém há de se ter uma preocupação o quanto antes, já que terá de se pôr e afirmar que não está ali como ator apenas por ter um rosto bonito e consecutivamente vender a partir de sua imagem. O artista ou celebridade, tem que procurar se esforçar e aperfeiçoar mais, para que o trabalho e talento convençam antes de qualquer outro fator externo.

O ator passa a ter duas vidas, a dele enquanto ator em seu ofício e a do ator como figura pública, isso faz com que a confusão entre as duas coisas seja mais frequente e a preparação geral para viver qualquer papel não comece somente ao saber o personagem, mas bem anteriormente, na própria formação dos atores. A verdade deve ser trabalhada para a desconstrução e revelação de si. No Brasil algumas instituições educacionais formadoras de atores, recentemente passaram a adotar ao final de seus cursos uma banca, tendo como convidados avaliadores profissionais conceituados nos cargos de produtores de elenco, pesquisadores de casting de emissoras ou independentes, eles são os coordenadores pela organização 
e seleção de atores e atrizes, como para uma obra na televisão. Essa banca recebe o nome de "Showcase". Um dos locais em que a prática ocorre é na Faculdade CAL de Artes Cênicas e na CAL - Casa de Artes de Laranjeiras (Rio de Janeiro), em que o showcase não se define apenas pela apresentação das contracenações entre alunos (atores), fazer isto é só o final do processo.

O showcase faz parte de uma disciplina opcional da matriz curricular dos cursos profissionais oferecidos, para o ator ficar mais adentro da linguagem estética de interpretação para a televisão. Quanto mais se aproxima do período exato com a banca a ser realizada, outra fase se desenvolve, prévia, a do trabalho de preparação de atores, que auxilia as duplas ou os trios de atores para que sejam convincentes no momento ao entrar na sala com a banca reunida, desde sua apresentação pessoal e a relação com a cena mostrada. É trabalhado para que os atores, depois de terem a cena que farão, não decorem o texto, mas tenham o entendimento da cena no todo, e a forma que ele vai fazer tem de caber por um jeito que não demonstre estar em um formato. O texto é o que menos importa. Verificar que o ator estar no universo vale mais. Isto feito, um mesmo objetivo de cena pode acontecer das mais variadas formas e não somente daquela óbvia que o texto possa sugerir. Muito dos personagens que os atores fazem possuem a tendência de se encontrarem daquilo mais perto do que aparentam para uma massa, o que relembra o "physique du rôle" próprio do cinema.

Involuntariamente, as alusões dos exercícios utilizados nesse projeto de e as questões textuais são muito similares as que Fátima Toledo usa. E ainda que no showcase possam vir por outras influências (incluindo vindas do estrangeiro), pelo fato de não ter registros anteriores, ao menos no Brasil, Fátima fica qualificada como a primeira em utilizar a metodologia principal aplicada, em relação a textos e afins, para colocá-los por último. Assim, por Toledo ainda possuir pessoas que indagam seu Método, a execução de exercícios onde ela é, queira ou não, a pioneira no país, sendo usados por outros treinadores de atores, como para o intuito de alunos serem avaliados e contratados, em priori, pela maior emissora de televisão do país, quer dizer por critério corroborado que suas escolhas nunca estiveram erradas.

Como fora indicado, o showcase equivale em uma avaliação feita por produtores de elenco. Para muitos dos atores é inclusive um primeiro contato direto com profissionais que podem chamá-los para atuarem em alguma obra audiovisual 
efetiva. Assim, é válido comparar como um teste, audição, sendo que na maioria dos participantes o nervosismo toma conta e a pessoa (ator) na hora de apresentar sua cena acaba se deixado tomar por outras questões externas que, de alguma forma, interferem na capacidade de sua interpretação, levando-a para uma não vivência em cena, uma isolada leviana atuação, com talvez improvisações arriscadas. Em justaposição, amiudadamente, se constata que a preparação para o showcase deve ser considerada como um julgamento de competência, minimizando e eliminando um possível pensamento do ator sobre personagens e trabalhos futuros, inexistentes. Mas sim como uma oportunidade para que isso venha a ocorrer. Portanto dar maiores créditos para as preparações realizadas antes é dar creditação para se viver nesta "audição", transpondo um momento de magia na interpretação. A atriz hollywoodiana Elle Fanning fez uma pertinente fala sobre audições:

\begin{abstract}
Audição, para mim, é algo muito estranho. Eu faço pressão sobre mim mesmo e sou uma espécie de perfeccionista e quero fazer o certo, imediatamente. As audições para mim são tão bizarras, porque leva um tempo para você encontrar esse personagem e para ele ser perfeito. E a pressão é que você precisa ter esse personagem imediatamente. E eu nem conheço nenhum desses estranhos que se encontram ali: O Diretor, o produtor, o câmera; que estão esperando que eu faça esse tipo de truque de mágica para eles. Normalmente o que você precisa fazer pode ser bastante intenso, emocionalmente; você tem que tocar em todo esse sentimento para as pessoas que você acabou de conhecer. Você diz. 'Olá!' E então você começa a chorar. Tipo, é um pouco estranho. (FANNING, 2017, não paginado, tradução nossa).
\end{abstract}

Reafirma-se um entendimento para não se fingir que é, mas estar e ser presente, porque a subjetividade de avaliação, já no caso de um filme, depende tanto quanto de perfil específico sob o que o responsável pela escalação de um elenco visualiza com sutileza para dar vida naquele roteiro já pré-estabelecido. Como Fanning focou, se leva um tempo para se achar em um personagem, para vivê-lo no período em que será trabalhado. Tratando-se do showcase, é uma avaliação / audição que pode abrir portas na televisão, para os mais variados tipos de trabalho e personagens, então o primordial é seguir tendo o foco pela busca ao estado fiel de presença e a certeza na segurança do ator x personagem na cena em que ele irá mostrar, seja qual for o contexto da mesma. Pois se os produtores de elenco especialistas não acreditarem no que está sendo apresentado, dificilmente centenas 
de milhões de telespectadores acreditarão nas telas. Depois desta primeira etapa sendo feita, com a procura de tais viabilidades, tão somente poderá pensar e se envolver para com o restante das preparações e construções que o ator terá que fazer para um personagem. Uma declaração valorosa, analítica e de cruel verdade expressada por Marlon Brando, colabora:

\begin{abstract}
As pessoas que vão ao teatro percebem as coisas de forma diferente. Você tem que oferecer algo ao público para receber algo em troca. Posso te dar o exemplo perfeito. Num filme que fiz, chamado Sindicato de ladrões, havia uma cena num táxi, na qual eu me virava para o meu irmão, que se tornara um gângster e me lamentava dizendo que ele nunca havia cuidado de mim, que nunca havia me dado uma chance, que eu poderia ter sido um competidor, poderia ter sido alguém em vez de um vagabundo... 'You should have looked after me, Charley.' Era muito emocionante. $\mathrm{E}$ as pessoas se referiam a ela como uma cena maravilhosa. $E$ não era nem um pouco. A situação é que era maravilhosa. Todos sentem como se pudessem ter sido competidores, como se pudessem ter sido alguém; todos sentem como se fossem em parte vagabundos. Talvez não vagabundos, mas não se sentem realizados e têm a sensação de que poderiam ter sido alguém melhor. $E$ foi isso que tocou as pessoas. Não a cena em si. Existem outras cenas nas quais atores tiveram performances especiais, mas como o espectador não se identificou, passaram desapercebidas. Cenas maravilhosas nunca são mencionadas, só as que afetam as pessoas. (COMPARATO, 2015, p. 22).
\end{abstract}

\title{
4 CONSIDERAÇÕES FINAIS
}

Fica tracejada a forma transcendental do tocante poder ao trabalho de um ator que o Método de Fátima Toledo atinge enormemente. Alguns dos atores nos filmes de sucesso que ela preparou estiveram marcados por mais de 30 anos, muitas vezes sendo reconhecidos principalmente pelo personagem que fizeram e não como cidadãos, artistas em sua identidade original. A típica confusão feita pela audiência, entre criador $x$ criatura. A situação pode ainda se fazer no caso de um ator que só tenha feito uma obra artística durante sua vida e apesar disso ser reconhecido, supondo que o resultado de uma preparação potente é influenciado ao panorama ator $x$ personagem $x$ interpretação. Isso é um fator da força do trabalho colocado por Fátima, do qual precisa ser muito bem e cuidadosamente feito, pois se trata de eternizar uma imagem e causar emoções sempre que assistido, inigualavelmente.

A interpretação de atores não pode ser uma ordem fechada e deve estar livre para as escolhas deles. Fátima, em toda a sua trajetória, sempre trabalhou nessa estrutura profissional. $O$ trabalho do ator sem ser uma obrigação, nem mesmo quando 
das indicações do diretor, na medida em que este último tem de ser responsável pela melhor organização e construção geral e não um soberano do projeto com vigor de alteração significante para a autonomia criativa do intérprete. Todavia, quanto à estética para o ofício do ator, é preciso que seja direcionada. As preparações só aumentam a estética que o ator já tem existente como bagagem, para que se tenham bonitas, satisfatórias e reinventadas interpretações, atingindo assim a literalidade do que se pode chamar por reais atuações e deixando o fluxo do diretor com os atores acontecer de forma mais qualitativa possível. No filme "A Paixão de Joana d'Arc 27", a interpretação da protagonista, desta que é uma obra-prima do cinema, foi feita pela excelente atriz (até então teatral) Renée Falconetti - que interpretou Joana d'Arc. Um filme mudo, aonde numerosos indivíduos no mundo consideram o trabalho de atuação da artista como a mais bela, potente e melhor interpretação da história do cinema. O mais curioso é que este foi o primeiro e único filme feito por Renée. Em uma conversa com Vinícius de Moraes ela disse:

Foram cinco meses de tortura. Às vezes brigávamos. Perguntava-lhe: "Mas $\mathrm{m}$. Dreyer, se o senhor me deixasse um pouco de liberdade para a ação, eu poderia dar alguma coisa de mim mesma". Ele recusava-se formalmente. Obrigava-me à maior passividade. Filmava coberto por anteparos, para que ninguém me visse e nada me distraísse a atenção do que fazia. Acabada a cena, recolhia-me a uma casa de campo a que só ele tinha ingresso. Falavame constantemente, incutindo-me a idéia da obra que queria realizar. Era-Ihe uma idéia fixa. Não foi à toa que enlouqueceu. Está internado. No dia em que acedi a que me raspassem a cabeça, coisa que ele me pedia sempre, foi de uma extraordinária doçura comigo. Mas nunca o vi tão áspero como quando, desobedecendo a uma ordem expressa sua, dei uma fugida a ver a Joana d'Arc de $\mathrm{m}$. Shaw. Ele soube e correu atrás de mim. Censurou-me amargamente de querer destruir-lhe o trabalho. "Agora...", disse-me, "vai sair a Joana d'Arc de Shaw, e não a minha!" (...) Nunca mais quis fazer outro filme. Tive propostas para Hollywood, mas não as aceitei. Acabei o trabalho num estado de nervos inimaginável. Ao ver o filme pela primeira vez, detestei-o. Não havia nada meu. Era tudo de m. Dreyer. Cinema é isso, é o diretor. (MORAES, 1942, não paginado).

Esses interessantes e intensos posicionamentos feitos pela atriz são de grandiosa valia do ator para a elaboração de um papel e das camadas anexadas ao entendimento de propriedade. É possível visualizar que um artista sob o mando de um diretor que oferecia pouquíssimas brechas para a construção do trabalho de

${ }^{27}$ Filme dirigido por Carl Theodor Dreyer, em 1928. 
interpretação e pode estar nos momentos das filmagens em um estado pleno de presença. Porém com a ressalva de que o ator estará em uma vivência da qual ele não tem tanto controle como gostaria e esta é enormemente importante.

Viver uma situação onde a capacidade autoral de um ator é mínima pode resultar em uma possível boa atuação, mas a partir do momento em que a esfera psíquica do ator se torna oprimida demais e o artista sente que não está com a liberdade que pleiteava, isso talvez acarrete que estado mental de um vulgo ator venha a interferir na vivência do personagem, ou inclusive ficar despropositadamente sem se separar dele (personagem) nos momentos de cortes, pois a pressão psicológica ainda estará causando efeitos, porventura ou automaticamente.

Nos dias presentes e futuros, seja em qual for a expressão artística e linguagem da cena, contudo sobressaindo o cinema e audiovisual, é inegável ponderar que ter o apoio condicional de uma preparação de elenco por Fátima Toledo e/ou pelos moldes de seu Método, leva todos a essencialidade de rever a relevância da cuja especialidade.

\section{REFERÊNCIAS}

ALVES, Luísa de Almeida Rocha. Sanford Meisner: O Exercício da Repetição e seus desdobramentos na formação técnica do ator. 2016. Trabalho de Conclusão de Curso (Bacharelado em Teatro) - Faculdade CAL de Artes Cênicas, Instituto CAL de Arte e Cultura. Rio de Janeiro, 2016.

CARDOSO, Maurício. Fátima Toledo: interpretar a vida, viver o cinema. São Paulo: LiberArs, 2014.

CASSEL, Vicent. Vincent Cassel: "a tv aqui é tipo uma máfia". [Entrevista cedida a] Diógenes Muniz. Segunda parte da entrevista. Revista Trip, Rio de Janeiro, 17 fev. 2016. Disponível em: Disponível em: https://revistatrip.uol.com.br/trip-tv/o-astrofrances-vincent-cassel-critica-a-tv-brasileira. Acesso em: 30/03/2018.

CIUDAD DE DIOS: formación de personajes. [Rio de Janeiro]: o2 filmes, 2002. 1 vídeo (52 min). Disponível em: https://www.youtube.com/watch?v=5uPI-iWAnNA. Acesso em: 30/03/2018.

COMPARATO, Bianca. Brando: O ator no cinema. Rio de Janeiro: Caixa Cultural, 2009. Disponível em: http://www.brunabenvegnu.com/BRANDOcatalogoMENOR.pdf. Acesso em: 20/06/2018. 
FANNING, Elle. Elle Fanning Talks About Auditions and Doubt. [Entrevista concedida a] Scott Cardy. Mental Makeover, Hollywood, 2017. Disponível em: https://www.youtube.com/watch?v=F2pyjhU9 j8. Acesso em: 12/06/2018.

HAMPTON, Debbie. What's the difference between feelings and emotions?. The best brain possible. [S.I], 12 jan. 2015. Disponível em:

https://www.thebestbrainpossible.com/whats-the-difference-between-feelings-andemotions/. Acesso em: 12/06/2018.

MARCADÉ, Émilie. Les différences de pratique dujeu d'acteur, danslescréations de jeu de fiction, enfonction de lascène et de l'écran. 2018. Dissertação (Mestrado em Comunicação) - Université du Québec à Montréal. Montréal, Canada, 2018. Acesso em: 20/06/2018.

MENDES, Bete. Bete Mendes: 'A melhor coisa que existe é viver, experimentar'. [Entrevista concedida a] Gustavo Leão. Revista Quem. [Rio de Janeiro], 14 maio 2012. Disponível em:

https://revistaquem.globo.com/Entrevista/noticia/2012/05/edicao-553-11042011melhor-coisa-que-existe-e-viver-experimentar.html. Acesso em: 20/06/2018.

MORAES, Vinicius de. Entrevista com mme. Falconetti, a grande intérprete de Joana d'arc do cineasta Carl Dreyer, bem como o seu pronunciamento no debate sobre cinema silencioso e cinema falado. A Manhã, Rio de janeiro, 9 jun.1942. Disponível em: http://www.viniciusdemoraes.com.br/en/cine/entrevista-com-mme-falconettigrande-interprete-de-joana-darc-do-cineasta-carl-dreyer-bem-como. Acesso em: 20/06/2018.

PEREIRA JR., Alberto. Globo vive descontrole de aproveitamento de seu elenco, afirma Boni. Entrevistado: Jose Bonifácio de Oliveira sobrinho. Folha de São Paulo, São Paulo, 15 jan. 2014. Disponível em:

https://f5.folha.uol.com.br/televisao/2014/01/1397751-globo-vive-descontrole-deaproveitamento-de-seu-elenco-afirma-boni.shtml. Acesso em: 30/03/2018.

STANISLAVSKI, Constantin. A Preparação do Ator. São Paulo: Civilização Brasileira, 1994. 